\title{
Range of atrioventricular conduction disturbances in Lyme borreliosis: a report of four cases and review of other published reports
}

\author{
Marcel R van der Linde, Harry J G M Crijns, Jos de Koning, \\ Jacomina A A Hoogkamp-Korstanje, Jacob J de Graaf, D Albertus Piers, \\ Albert van der Galiën, Kong I Lie
}

\begin{abstract}
Four patients with Lyme borreliosis had atrioventricular conduction disturbances. All four were positive for specific antibodies against Borrelia burgdorferi measured by indirect immunofluorescence tests. Biopsy specimens, which were obtained in three patients, showed bandlike infiltrates of plasma cells and lymphocytes in the endocardium. There was diffuse infiltration of the interstitium of the myocardium by lymphocytes, plasma cells, and macrophages. In two patients single fibre necrosis was seen in the myocardium. Biopsy specimens of the heart showed spirochetes in all three patients and serial sections stained by the BosmaSteiner technique showed that they resembled Borrelia burgdorferi. At follow up one patient had persistent complete atrioventricular block, despite treatment with antibiotics and corticosteroid, and a permanent pacemaker was implanted.
\end{abstract}

Department of Cardiology, Thoraxcenter, University Hospital, Groningen, The Netherlands $M R$ van der Linde M J van Crijns $A$ van der Galiën K I Lie

Department of Pathology and Microbiology, Laboratory for Public Health, Leeuwarden, The Netherlands $\mathrm{J}$ de Koning

J A A HoogkampKorstanje

Department of Cardiology, Nij Smellinghe Hospital, Drachten,

The Netherlands

$J$ J de Graaf

Department of

Nuclear Medicine,

University Hospital,

Groningen,

The Netherlands

D A Piers

Correspondence to

Dr Marcel $R$ van der Linde, Department of Cardiology, Thoraxcenter, University Hospital, Groningen, Oostersingel 59, 9713 EZ Groningen

The Netherlands.

Accepted for publication 21 September 1989 skin, joints, nervous system, and the heart. ${ }^{5-8}$ The disease is found throughout the world but it is especially prevalent in wooded areas of Europe and North America. ${ }^{6}$ Lyme borreliosis occurs in three stages with different clinical manifestations. ${ }^{5-7}$ In the second stage the heart can be affected, causing atrioventricular block, rhythm disturbances, heart failure, acute myopericarditis, and pancarditis. Cardiac manifestations in Lyme borreliosis were reported in $8 \%$ of North American patients. ${ }^{9}$ In Europe, however, the frequency of Lyme carditis is not well established yet.

We describe four patients with Lyme borreliosis in whom atrioventricular conduction disturbances caused the main symptoms. They were studied in 1987 and 1988.

\section{Patients and methods}

PATIENT 1

A 40 year old athlete was admitted with complete atrioventricular block of unknown origin and a 2 day history of recurrent dizziness and near collapse. For 3 weeks he had had pain and stiffness in four toes of his right foot. He could not recall a tick bite. At physical examination there were no abnormalities, except for a first heart sound of variable intensity and warm, red, and painful toes. The surface electrocardiogram showed a complete atrioventricular block with an escape rhythm of 37 per min and a QRS configuration suggesting a focus in the left bundle branch. The $P$ wave configuration was abnormal and the P wave was long. Despite treatment with atropine and isoprenaline he had recurrent periods of ventricular standstill lasting up to 10 seconds. The erythrocyte sedimentation rate was $22 \mathrm{~mm}$ in one hour. Chest radiographs and the echocardiogram were normal. A gallium- 67 scan showed diffuse uptake in the myocardium (fig la-c). Serological tests for Borrelia burgdorferi were positive for IgM and weakly positive for IgG (table). Tests for Chlamydia and cytomegalovirus were weakly positive but the titre did not increase. Serological markers for other microorganisms and diseases were all negative, including the Treponema pallidum haemagglutination assay, streptococcal antibody tests, tests for several viruses (coxsackievirus, echovirus, adenovirus, influenza $A$, hepatitis B), rheumatoid factor, and antinuclear antibodies. After giving informed consent, the patient underwent endomyocardial biopsy and serial electrophysiological studies.

A 23 year old previously healthy woman was admitted because of a tonic-clonic seizure with collapse, diagnosed as a grand mal epileptic seizure. She could not recall a tick bite. Physical examination showed no abnormalities except a first heart sound of variable intensity. The electroencephalogram and computed tomogram of the brain were normal. A surface electrocardiogram showed complete atrioventricular block with a ventricular escape rhythm of 40 per minute and giant $T$ wave inversion (figure 2). Routine laboratory tests, chest radiographs, and the echocardiogram were normal. Serological tests were positive for Borrelia burgdorferi (table) and negative for other micro-organisms. After informed consent was obtained, we performed an electrophysiological study and took endomyocardial biopsy specimens.

\section{PATIENT 3}

This 30 year old man had removed ticks from 
Figure 1 Scan of patient 148 hours after intravenous injection of $100 \mathrm{MBq}$ gallium-67. (a) anterior, (b) left lateral, and (c) posterior views showing increased uptake in the cardiac wall.
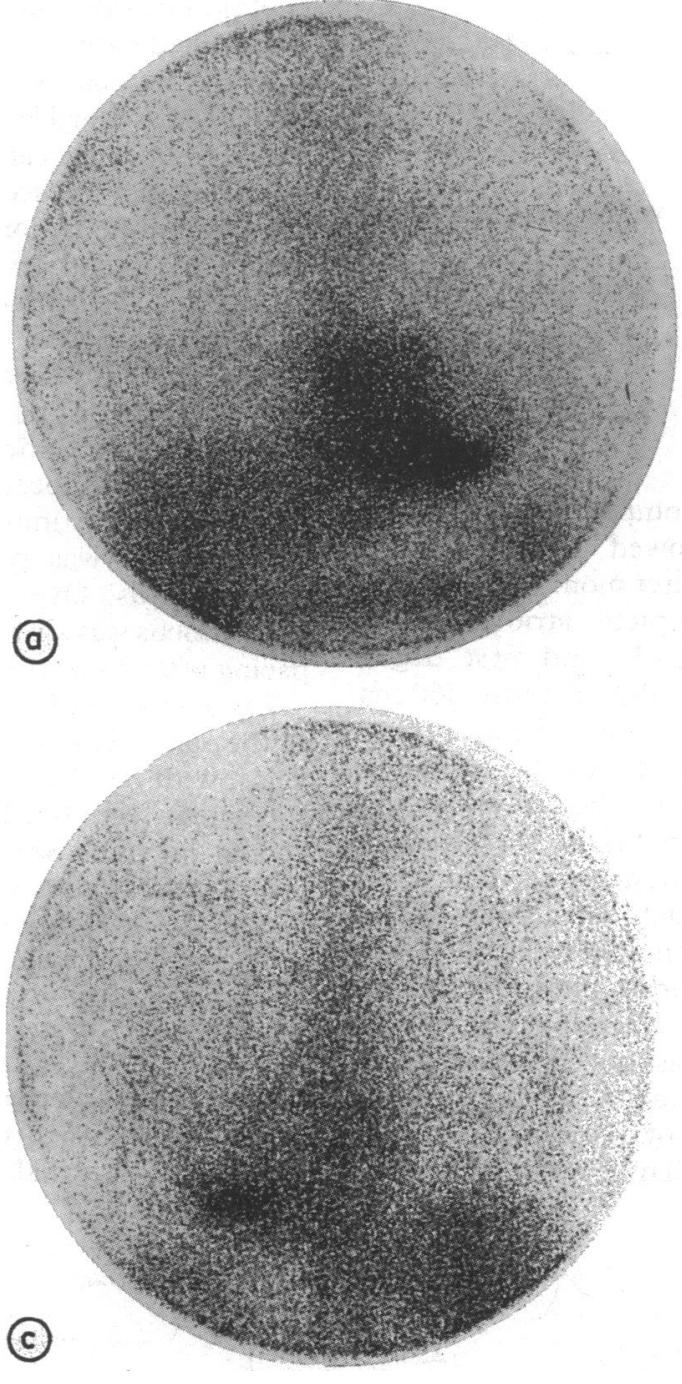

his cat but did not recall a tick bite. In the next three weeks he felt ill, had abdominal pain, and discovered a red spot $(10 \mathrm{~cm}$ wide $)$ on the right side of his face, which resembled erythema migrans and disappeared spontaneously after 6 days. Since then he had slight fever, pain in

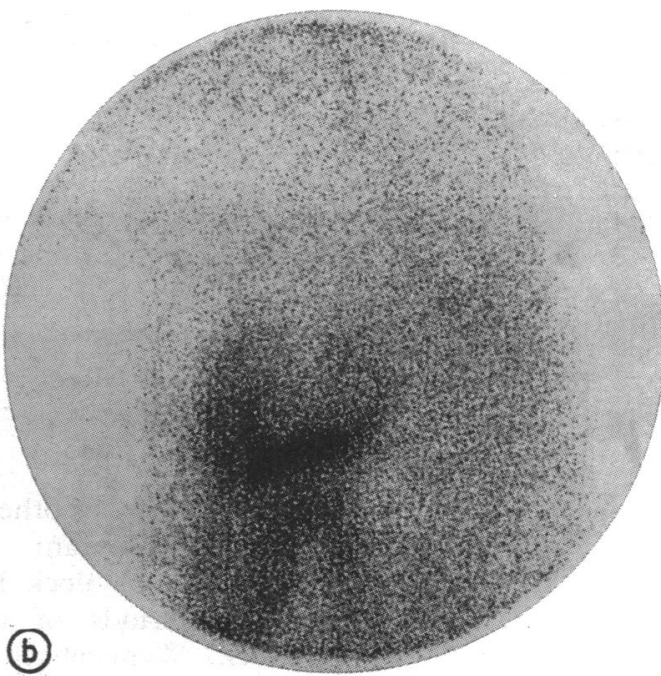

both knees, dizziness and fatigue on exertion, and a pulse rate of 36 beats $/ \mathrm{min}$. An electrocardiogram showed a complete atrioventricular block with a junctional escape focus of 38 beats min. A 24 hour Holter recording showed first degree, second degree, and advanced atrioventricular block, with rapid transitions from one type of block to the other. The longest RR interval was 2.8 seconds. At admission serological tests for Borrelia burgdorferi were positive for both IgM and IgG (table). Routine laboratory tests and chest $x$ ray were normal. An echocardiogram showed slight hypokinesis of the most proximal part of the intraventricular septum, but the gallium scan did not confirm the suspicion of inflammation (the gallium scan showed no uptake). After the patient gave informed consent, we performed an electrophysiological study and took endomyocardial biopsy specimens.

\section{PATIENT 4}

A 34 year old previously healthy male nurse had arthritis of one toe of his right foot for three weeks. Thereafter he noticed palpitation, with-

\section{Data on the four patients with Lyme borreliosis}

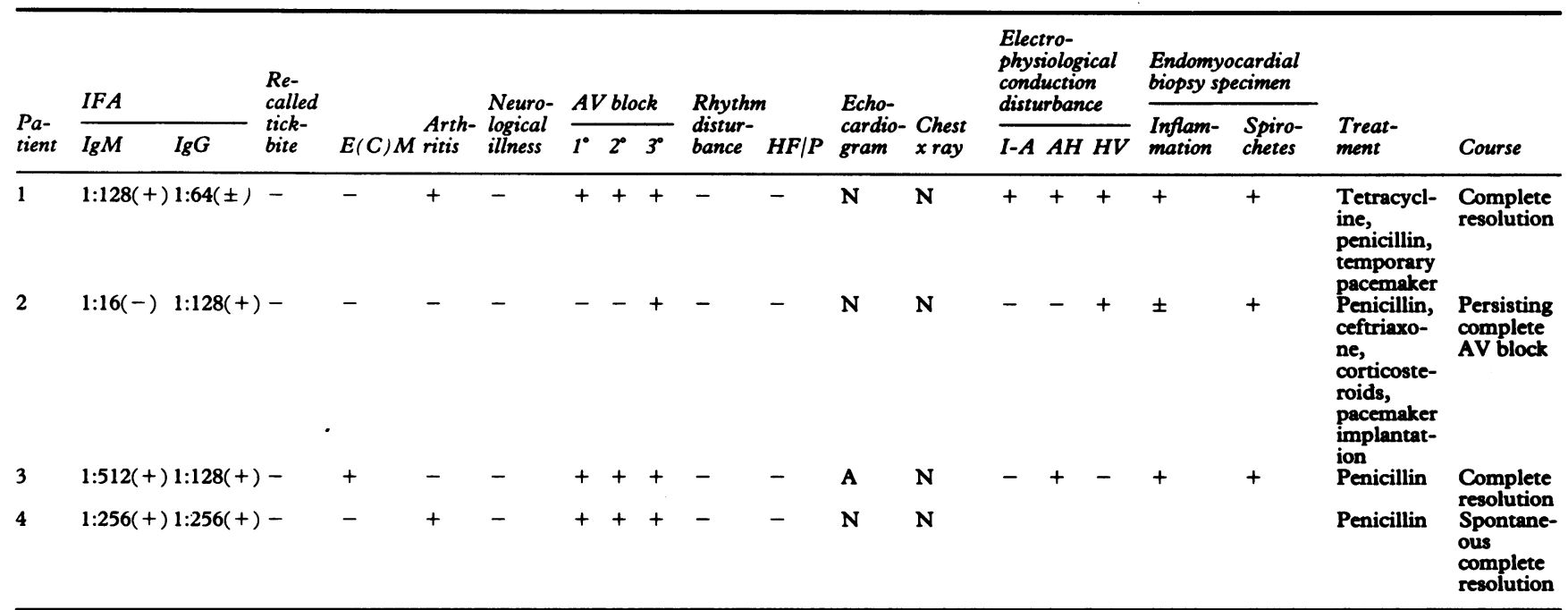

IFA, immunofluorescence assay; E(C)M = erythema (chronicum) migrans; AV block, atrioventricular block; HF/P, heart failure/pericarditis; I-A, intra-atrial;

+ , positive/present; \pm , weakly positive; - negative/absent; $A$, abnormal; $N$, normal.
Antibody titres of Borrelia burgdorferi determined with indirect immunofluorescence assay; positive titre for IgM antibodies $\geqslant 1: 64$ and for IgG antibodies $\geqslant 1: 128$ (Laboratory for Public Health, Department of Pathology and Microbiology, Leeuwarden, The Netherlands). 
Figure 2

Electrocardiogram of patient 2 on admission showing complete atrioventricular block and giant negative $T$ waves in leads $V 2$ and $I, I I, V 6$ $\left(Q T_{c} 474 \mathrm{~ms}\right.$ )

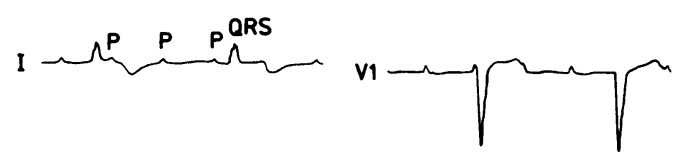

II

III

out dizziness or other complaints. The surface electrocardiogram showed atrioventricular Wenckebach block. Holter monitoring showed short periods of complete atrioventricular block, Wenckebach block, and first degree atrioventricular block (PQ interval $360 \mathrm{~ms}$ ) with rapid transition from one type to another. The patient was admitted for further investigation. Physical examination showed only slight signs of arthritis of the right toe. Routine laboratory tests, the chest $x$ ray, and echocardiogram were normal. At admission the surface electrocardiogram had reverted to normal and further monitoring did not show any rhythm abnormalities. Therefore an electrophysiological study was not performed nor were biopsy specimens taken. Serological tests showed clear evidence of Borrelia burgdorferi antibodies (table) and all other serological tests were normal.
ELECTROPHYSIOLOGICAL STUDIES

We studied patients in the postabsorptive state with $4 \mathrm{~F}$ bipolar (Cordis) catheter electrodes designed to record His bundle potentials. After positioning of the catheter across the tricuspid valve under fluoroscopic guidance we mapped the His bundle region to characterise the conduction of the atrioventricular node and $\mathrm{His}$ bundle and determine the site of the block. In addition, we placed two quadripolar (USCI) catheter electrodes, one in the high right atrium and one in the right ventricular apex. Signals were directly recorded with a Gould ES 1000 recorder, paper speed at $100 \mathrm{~mm} / \mathrm{s}$. Programmed electrical stimulation in the right ventricular apex was performed with only one extrastimulus. Overdrive suppression of the escape focus was always interrupted by back up pacing after 3 seconds.

Endomyocardial biopsy specimens were taken at the same session through the right jugular vein with a $7 \mathrm{~F}$ Cordis bioptome. The specimens were fixed in formalin and embedded in paraffin. Serial sections were cut and every fifth section was stained by a routine technique. All other slices were stained with a modified silver stain to screen the sections for micro-organisms. ${ }^{10}$

\section{Results}

We performed electrocardiographic follow up studies on all patients and electrophysiological and endomyocardial biopsies in three of the four patients.
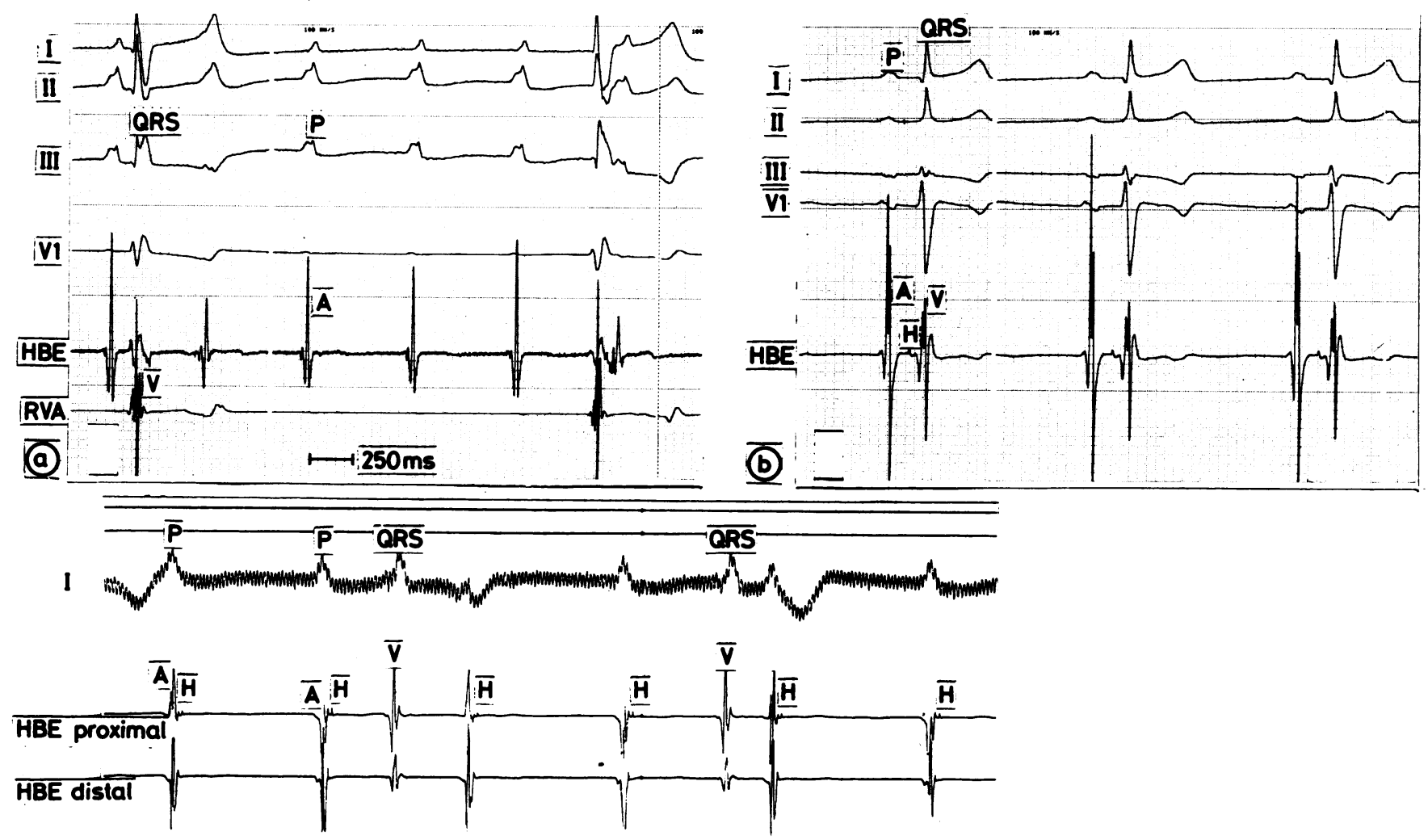

(c)

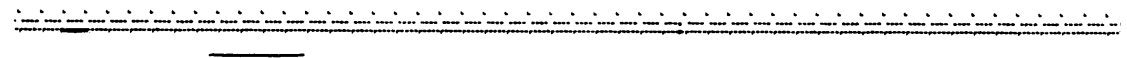

Figure 3 Electrophysiological recordings showing (a) complete atrioventricular block in patient 1 with no His bundle activity ( $P$ wave duration $120 \mathrm{~ms}, Q R S$ duration $130 \mathrm{~ms}$ ), (b) first degree atrioventricular ilock (PR interval $280 \mathrm{~ms}$ ) and a small positive-negative His bundle spike in patient 1 ( AH interval $155 \mathrm{~ms}$, $\mathrm{HV}$ interval $45 \mathrm{~ms}$, $P$ wave duraition $100 \mathrm{~ms}$, QRS duration $100 \mathrm{~ms}$ ). Electrophysiological recordings (c) in patient 2 showing complete atrioventricular block and (only positive) His bundle activity ( $A H$ interval 85 ms). A, atrial activity; $H, H i s$ spike; $H B E, H i s$ bundle electrocardiogram; RVA, right ventricular apex; $V$, ventricular activity. 
Figure 4

Endomyocardial biopsy specimen from patient 1. (a) Showing diffuse interstitial infiltrates of lymphocytes, plasma cells, and some macrophages in the myocardium (original magnification, $\times 250$, haematoxylin and eosin). (b) A black-stained spirochete between the muscle fibres (original magnification, $\times 1250$, Bosma-Steiner staining).

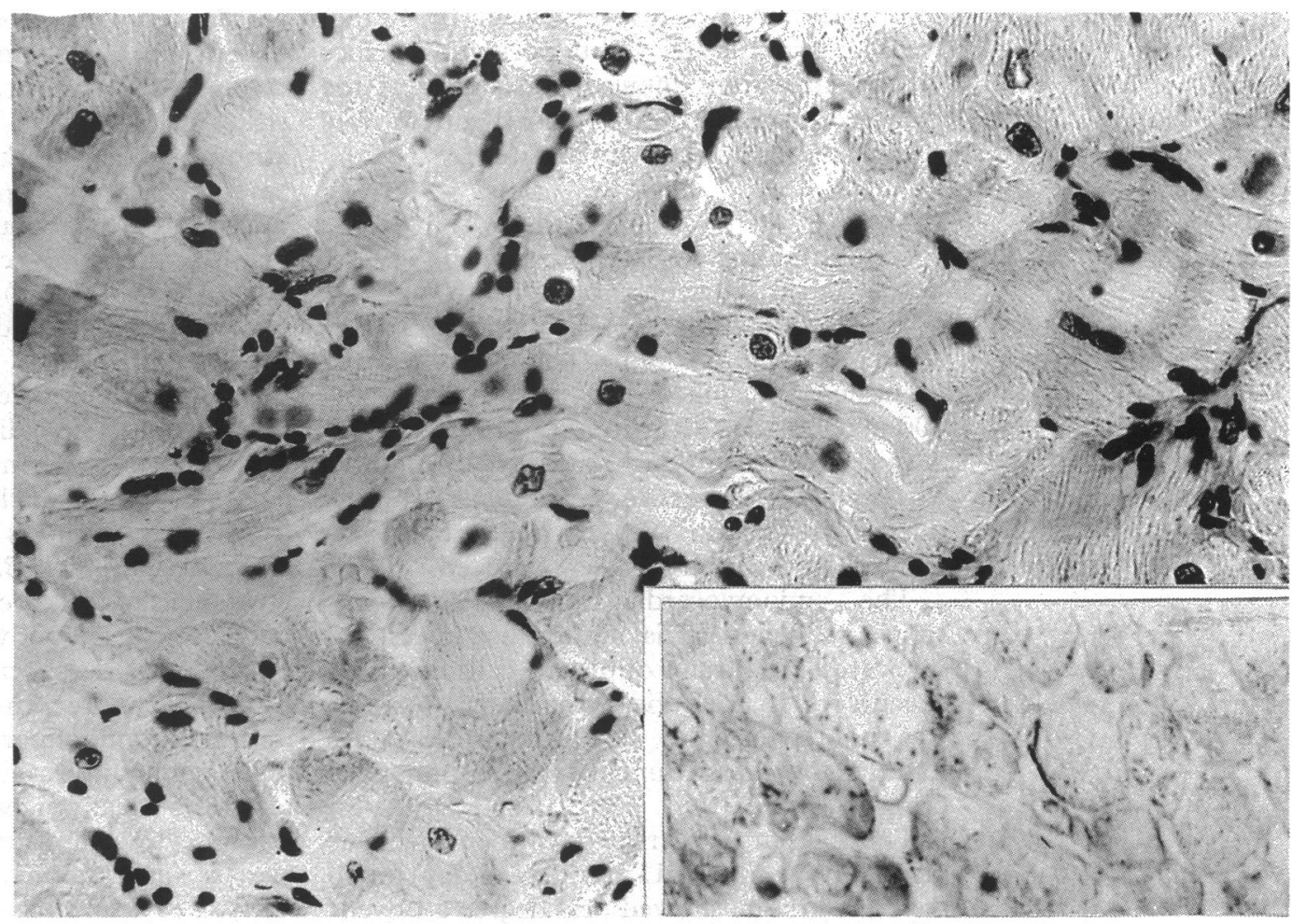

PATIENT 1

Patient 1 underwent serial electrophysiological investigations. The first electrophysiological study, performed in the acute phase with complete atrioventricular block, showed no His bundle activity despite extensive mapping of the His bundle region with several types of catheter electrodes. The QRS configuration and duration (130 ms) were compatible with an (unstable) escape focus in the left bundle branch. Additionally, the abnormal $\mathbf{P}$ wave configuration and duration of $120 \mathrm{~ms}$ suggested a prolonged intra-atrial conduction time (figure 3a). There was no retrograde ventriculoatrial conduction, either spontaneous or during ventricular pacing. No ventricular or supraventricular tachycardias were induced.

The finding of a diffuse lymphoplasmacytic infiltrate and scattered macrophages in the myocardium accorded with the gallium-67 scan. A few small infiltrates were found around single myocytes that showed early stages of necrosis. In the oedematous endocardial region plasma cells and lymphocytes formed infiltrates of varying thickness. Vascular alterations were not demonstrable. A few spirochetes were seen between the muscle fibres (figure 4). ${ }^{11}$ In combination with the serological results this indicated Lyme carditis.

A temporary pacemaker was inserted and the patient was treated with oral tetracycline (500 mg four times a day); after 5 days this was changed to intravenous penicillin ( 4 million IU four times a day for 14 days). Between the 6 th and 10th days after admission the disturbances of atrioventricular conduction resolved to a second and later to a first degree atrioventricular block on the surface electrocardiogram. The electrophysiological study was repeated in the recovery phase. His bundle activity was now easily found, the intra-atrial conduction delay had disappeared, and the duration of the
QRS complex was normal. The AH interval was slightly prolonged, but the $\mathrm{HV}$ interval was normal (figure 3b).

After three weeks of antibiotic treatment the patient was discharged with a normal surface electrocardiogram and minor residual complaints of arthritis.

\section{PATIENT 2}

Electrophysiological study showed a small positive His bundle deflection without a negative deflection at all sites mapped in the His bundle region. The $\mathrm{AH}$ interval was normal, but there was no relation between His bundle activity and QRS complexes (figure 3c). There was no retrograde ventriculoatrial conduction. No ventricular or supraventricular tachycardias were induced. The myocardial biopsy specimens showed small diffuse focal infiltrates of plasma cells and lymphocytes mixed with some macrophages as is seen in other affected organs in the second stage of Lyme borreliosis. Typical band-like infiltrates of plasma cells and lymphocytes were seen in the endocardium. Single muscle fibre degeneration was found in association with small infiltrates of mononuclear cells. Spirochetes were demonstrable in the interstitium by the Bosma-Steiner silver stain. ${ }^{11} 11$ The patient was treated with intramuscular penicillin ( 5 million IU three times a day) for 14 days. Six weeks later a 48 hour Holter scan showed persistent complete atrioventricular block with a ventricular escape rhythm of 32 beats $/ \mathrm{min}$. At a bicycle exercise test there was too small an increase in the patient's ventricular escape rhythm for her to attain a normal performance for her age.

Repeated serological tests for Borrelia burgdorferi were positive for IgG. Subsequently she was treated with intravenous ceftriaxone ( $2 \mathrm{~g}$ a day for 10 days) and oral prednisolone 
(40 mg/day in two doses, tapering by $10 \mathrm{mg} /$ week). After another seven weeks the surface electrocardiogram showed persistence of the complete atrioventricular block and a rate responsive pacemaker was inserted.

\section{PATIENT 3}

Electrophysiological study showed a first degree atrioventricular block with an $\mathrm{AH}$ interval of $340 \mathrm{~ms}$ and a $\mathrm{HV}$ interval of $45 \mathrm{~ms}$ at a heart rate of $92 \mathrm{~min}$. There was a large biphasic His spike. The $P Q$ interval was $400 \mathrm{~ms}$ and the QRS interval $110 \mathrm{~ms}$. There was a prolonged Wenckebach cycle length of $570 \mathrm{~ms}$. No retrograde ventriculoatrial conduction was found. No ventricular or supraventricular tachycardias were induced.

The endomyocardial biopsy specimens showed subendocardial and diffuse interstitial myocardial infiltrates of plasma cells and their precursors. In this patient necrosis of myocytes was not detectable. Few spirochetes were found in the interstitium between the muscular fibres.

The patient was treated with intravenous penicillin ( 5 million IU four times a day) for 10 days. At first he showed first degree atrioventricular block with rapid transition to complete atrioventricular block, but after 8 days of antibiotic treatment only first degree atrioventricular block was seen (PQ interval decreased to $280 \mathrm{~ms}$ ). After 10 days the patient was discharged without any complaints. One week after the end of antibiotic treatment the surface electrocardiogram was completely normal.

\section{PATIENT 4}

This patient was treated with intravenous penicillin (4 million IU four times a day) for 10 days. Eighteen months later he was well and the conduction disturbances did not recur.

\section{Discussion}

The clinical expression of Lyme borreliosis is highly variable. ${ }^{5-8}$ The most common and clinically most troublesome cardiac manifestation is atrioventricular block. ${ }^{56-15}$ Among patients with atrioventricular conduction disturbances caused by Lyme borreliosis $98 \%$ show first degree atrioventricular block, $40 \%$ Wenckebach periodicity, $50 \%$ complete atrioventricular block, and about $38 \%$ require a temporary pacemaker. Up to $65 \%$ of these patients show ST segment depression or $T$ wave inversion, depressed left ventricular ejection fraction, or cardiomegaly and pericarditis. ${ }^{6}$ Supraventricular arrhythmias such as atrial fibrillation occur occasionally ${ }^{16}$ and one patient can have atrioventricular block of several degrees. Occasionally the degree of atrioventricular block varies within minutes. ${ }^{61215}$ According to some the risk of complete atrioventricular block is much higher when the PR interval is $>300 \mathrm{~ms}^{917}$

The differential diagnosis of the causes of atrioventricular block includes other infections such as Treponema pallidum infection, diphtheria, Yersinia enterocolitica infection, virus infection (coxsackie A and B, echovirus type 6 and 8 , adenovirus type 3 , influenza $A$, hepatitis B, Epstein-Barr, mumps, poliomyelitis, varicella), toxoplasmosis, Chagas's disease, and rickettsial infections. Non-infectious causes of atrioventricular block are coronary artery disease, intracardiac operation, medication induced atrioventricular block, congenital heart disease, idiopathic sclerodegenerative disease (Lenègre's disease), fibrocalcareous enchroachment (Lev's disease), acute rheumatic fever, polyarthritis, systemic lupus erythematosus, amyloidosis, sarcoidosis, and myxoedema. These diseases are usually distinguishable from Lyme borreliosis by special laboratory tests and clinical findings. The tests for Lyme borreliosis measure IgM and IgG antibodies against Borrelia burgdorferi..$^{6-81819}$ Two types of tests are used: indirect immunofluorescence antibody tests and an enzymelinked immunosorbent assay (ELISA). The ELISA is more sensitive and specific than indirect immunofluorescence tests, which are more commonly available. ${ }^{18}$ Routine laboratory tests usually show a moderately increased erythrocyte sedimentation rate, slight leucocytosis, and raised total immunoglobulin. Chest $x$ rays and echocardiograms are usually normal.

Gallium scintigraphy can show increased uptake in the cardiac wall, which suggests endomycarditis. ${ }^{20-22}$ Histological detection of Borrelia burgdorferi organisms in tissue, blood, cerebrospinal fluid, and joint fluid is feasible, ${ }^{10112324}$ but seldom successful.

In adults early Lyme borreliosis (stage 1 ) is treated with oral tetracycline $(250 \mathrm{mg}$ four times a day) for 30 days and in stages 2 and 3 by intravenous ceftriaxone (2-4 $\mathrm{g}$ daily in one or two doses) or intravenous penicillin (20 million IU daily in 4-6 doses) for 10 days. ${ }^{6825-28}$ If atrioventricular block persists beyond a week treatment with corticosteroids is advised (40-60 $\mathrm{mg} /$ day, tapering by $5-10 \mathrm{mg} /$ week). ${ }^{7152529-31}$ The value of a single corticosteroid dose at the start of antibiotic treatment in reducing the risk of a Jarisch-Herxheimer reaction (temporary deterioration of the disease because of an overload of the immunosystem by toxic antigen) is uncertain.

Serological tests for Lyme borreliosis were positive in all four of our patients: patient 1 was positive for IgM antibodies, patient 2 for IgG antibodies, and patients 3 and 4 were positive for both (table). In patient 1 the gallium scan showed signs of endomyocarditis. In all the patients the atrioventricular conduction disturbances caused the main symptoms. In three patients $(1,2$, and 4$)$ the clinical presentation did not resemble the classic course of Lyme borreliosis in North American patients: our patients did not have erythema migrans and arthritis was restricted to the small joints and developed before the cardiac symptoms. Only patient 3 had erythema migrans and general malaise before the atrioventricular conduction disturbances developed (table). The clinical expression of Lyme borreliosis is known to vary considerably. In about $25 \%$ of the cases with Lyme arthritis there is no erythema migrans or it is not recognised. Sometimes 
patients present with neurological or cardiac symptoms. . $^{51432}$ Furthermore, the strain of Borrelia burgdorferi and the ticks are different in Europe (generally Ixodes ricinus) and in the United States (generally Ixodes dammini and Ixodes pacificus). ${ }^{33-42}$

The atrioventricular conduction disturbances were studied by serial surface electrocardiograms in all four patients and in three serial electrophysiological studies were also performed (figure $3 a-c$ ). In three patients we also took endomycardial biopsy specimens. The electrophysiological studies in patient 1 indicated that the atrioventricular block was located in the atrioventricular node, with accompanying conduction disturbances above (intra-atrial) and beneath (in the common His bundle) this site. This patient had a very unstable escape focus. The electrophysiological study in patient 3 also suggested a proximal site for the atrioventricular block, which was more local than in patient 1 . Giant T wave inversion, as shown on the electrocardiogram of patient 2 (figure 2), was described in other patients with Lyme borreliosis with more diffuse cardiac involvement ${ }^{69}$ but inverted $T$ waves were also described in patients who had had a period of circulatory arrest and cerebral hypoxaemia. ${ }^{43}$ The electrophysiological study in patient 2 showed no terminal negative deflection of the His spike, a normal AH interval, and no relation between His bundle activity and ventricular complexes (figure $3 c$ ). This shows that the site of the atrioventricular block may also lie in the distal part of the His bundle, leaving the proximal part undisturbed. Despite extensive treatment with antibiotics and corticosteroid ${ }^{91528-30}$ complete atrioventricular block persisted in this patient and a permanent pacemaker had to be implanted. We believe this to be the first reported case in which complete atrioventricular block caused by Lyme disease did not resolve. ${ }^{6}{ }^{12-15} 174445$

The biopsy specimens of the hearts of all three patients had the same appearance. The endocardial zone showed the plaque-like infiltrates of lymphocytes and plasma cells that are typical of cardiac involvement in Lyme borreliosis. ${ }^{46}$ There were interstitial infiltrates in the myocardium and sometimes signs of necrosis of single myocytes. The tissue of all three patients contained coiled structures typical of the Lyme spirochete. So far only Reznick et al have reported a "coiled structure, compatible with a spirochetal organism" in the endomyocardial biopsy specimen of a surviving patient. ${ }^{31}$ Marcus et al showed spirochetes in the myocardium at a necropsy in a patient with fatal pancarditis related to coexistent Lyme borreliosis and babesiosis. ${ }^{47}$

Both patients 3 and 4 showed spontaneous alteration in the degree of atrioventricular block. Patient 4 had a mild disturbance of atrioventricular conduction-that is short periods of complete atrioventricular block. $\mathrm{He}$ was treated with antibiotics and the atrioventricular conduction disturbances did not recur.

These four patients and a review of other reported cases lead to the following conclusions. In Lyme disease electrophysiological studies show that atrioventricular block can occur at different levels of the atrioventricular conduction system. Occasionally there are sinoatrial and intra-atrial conduction disturbances. Ventricular and supraventricular tachycardias seem to be less frequent than conduction disturbances. Spirochetes can be found by a special silver staining technique on the endomyocardial biopsy specimens of patients with Lyme carditis. Usually gallium67 scintigraphy and endomyocardial biopsies are not essential to the diagnosis of Lyme carditis. Where diagnosis is difficult, however, the combination of serological tests-that are positive for Borrelia burgdorferi-and the presence of spirochetes in endomyocardial biopsy specimens (proof of Lyme carditis) may influence the management of a patient, as shown by the extensive antibiotic treatment and late pacemaker implantation in patient 2 . It may be worth while to use the gallium scan to guide biopsy and increase the sensitivity of histological examination. ${ }^{48}$ When atrioventricular block of unknown origin develops suddenly, Lyme carditis must be considered, especially in younger patients. In most patients adequate treatment will avoid the need for a permanent pacemaker.

1 Steere AC, Malawista SE, Snydman DR, et al Lyme arthritis: an epidemic of oligoarticular arthritis in children and adults in three Connecticut communities. Arthritis Rhem 1977;20:7-17.

2 Steere AC, Malawista SE, Hardin JA, Ruddy S, Askenase PW, Andiman WA. Erythema chronicum migrans and Lyme arthritis. The enlarging clinical spectrum. Ann Intern Med 1977;86:685-98.

3 Steere AC, Malawista SE, Snydman DR, Andiman WA. A cluster of arthritis in children and adults in Lyme, cluster of arthritis in children and adults in Lym
Connnecticut [Abstract]. Arthritis Rhem 1976;19:824.

4 Burgdorfer W, Barbour AG, Hayes SF, Benach JL, Grunwaldt E, Davis JP. Lyme disease-a tick-borne spirowaldt E, Davis JP. Lyme disease
chetosis? Science 1982;216:1317-9.

5 Steere AC, Bartenchagen NH, Craft JE, et al. Clinical manifestations of Lyme disease. Zbl Bakt Hyg 1986; A263:201-5.

6 Goldings EA, Jericho J. Lyme disease. Clin Rheum Dis 1986;12:343-67.

7 Schned ES, Williams DN. Lyme disease. The tick bite, the rash and the sequelae. Postgrad Med 1985;77: 303-8, 310 .

8 Hechemy KE. Lyme disease: a review. Bull Soc Pathol Exot Filiales 1986;79:9-21.

9 Steere AC, Batsford WP, Weinberg M, et al. Lyme carditis: cardiac abnormalities of Lyme disease. Ann Intern Med 1980;93:8-16.

10 de Koning J, Bosma RB, Hoogkamp-Korstanje JAA Demonstration of spirochaetes in patients with Lyme disease with a modified silver stain. J Med Microbiol disease with a
$1987 ; 23: 261-7$

11 de Koning J, Hoogkamp-Korstanje JAA, van der Linde MR, Crijns HJGM. Demonstration of Lyme spirochetes MR, Crijns HJGM. Demonstration of Lyme spirochetes in cardiac biopsies of

12 van der Linde MR, Crijns HJGM, Lie KI. Transient complete atrioventricular block in Lyme disease. Chest 1989;96:219-21.

13 Houwerzijl J, Root JJ, Hoogkamp-Korstanje JAA. A case of Lyme disease with cardiac involvement in the Netherlands [Letter]. Infection 1984;12:358.

14 Kapusta P, Fauchier JP, Cosnau P, Huguet R, Grezard O, Rouesnel P. Troubles conductifs sino-auriculaires et auriculo-ventriculaires de la maladie de Lyme. A propos de deux observations. (Sinoatrial and atrioventricular conduction disorders in Lyme disease. Apropos of 2 case reports). Arch Mal Coeur 1986;79:1361-6.

15 Meyer LK, Swenson DB. Lyme carditis: high-grade hear block in Lyme disease. Minn Med 1987;70:345-6.

16 Ballmer PE, Hany A. Lyme-Karditis (Lyme carditis) Schweiz Med Wochenschr 1988;118:358-62.

17 Dunica S, Piette JC, Nassar N, Beaufils P. Une nouvelle cause de bloc auriculo-ventriculaire aiou transitoire: la cause de blo auriculo-ventriculaire af u transitoire: la maladie de Lyme. (A new cause of acute transitory 1986;79:1251-5.

18 Craft JE, Grodzicki RL, Steere AC. Antibody response in Lyme disease: evaluation of diagnostic tests. J Infect Dis 1984;149:789-95.

19 Magnarelli LA, Anderson JF. Early detection and persis- 
tence of antibodies to Borrelia burgdorferı in persons with Lyme disease. Zbl Bakt Hyg 1986;A 263:392-9.

20 Alpert LI, Welch P, Fisher N. Gallium-positive Lyme disease myocarditis. Clin Nucl Med 1985;10:617.

21 Rienzo RJ, Morel DE, Prager D, Barron L, Post R. Gallium avid Lyme myocarditis. Clin Nucl Med 1987;12 475-6.

22 Jacobs JC, Rosen JM, Szer IS. Lyme myocarditis diagnosed by gallium scan. J Pediatr 1984;105:950-2.

23 Durau PH. The surgical pathology of human Lyme disease. An enlarging picture. Am J Surg Pathol 1987;11(supp 1):47-60.

24 Steere AC, Grodzicki RL, Kornblatt AN, et al. The spirochetal etiology of Lyme disease. N Engl J Med 1983; 308:733-40.

25 Steere AC, Malawista SE, Newman JH, Spieler PN, Bartenhagen NH. Antibiotic therapy in Lyme disease. Ann Intern Med 1980;93:1-8.

26 Steere AC, Green J, Hutchinson GJ, et al. Treatment of Lyme disease. Zbl Bakt Hyg 1986;A263:252-6.

27 Steere AC, Green J, Schoen RT, et al. Successful parenteral penicillin therapy of established Lyme arthritis. $N$ Engl penicillin therapy of es $1985 ; 312 ; 869-74$.

28 Dattwyler RJ, Halperin JJ, Pass H, Luft BJ. Ceftriaxone as effective therapy in refractory Lyme disease. $J$ Infect Dis effective therapy in

29 Bedell SE, Pastor BM, Cohen SI. Symptomatic high grade heart block in Lyme disease. Chest 1981:79.236-7.

30 Olson LJ, Okafor EC, Clements IP. Cardiac involvement in Lyme disease: manifestations and management. Mayo Clin Proc 1986;61:745-9.

31 Reznick JW, Braunstein DB, Walsh RL, et al. Lyme carditis. Elecrophysiologic and histopathologic study. $\mathrm{Am} \mathrm{J} \mathrm{Med}$ 1986;81:923-7.

32 Bateman DE, White JE, Elrington G, Lawton NF. Three further cases of Lyme disease. Br Med J 1987;294:548-9.

33 Stanek G, Wewalka G, Groh V, Neumann R, Kristoferitsch W. Differences between Lyme disease and European arthropod-borne' Borrelia infections [Letter] Lancet 1985;i:401.

34 Parke A. From New to Old England: the progress of Lyme disease. Br Med J 1987;294:525-6.
35 Schmidt R, Kabatzki J, Hartung S, Ackermann R. Erythema chronicum migrans disease in the Federal Republic of chronicum migrans disease in the Federal

36 Stanek G, Flamm H, Groh V, et al. Epidemiology of Borrelia infections in Austria. Zbl Bakt Hyg 1986;A263:442-9.

37 Aeschlimann A, Chamot E, Gigon F, Jeanneret J-P, Kesseler D, Walther C. B. burgdorferi in Switzerland. $Z b$ Bakt Hyg 1986;A263:450-8.

38 Trevision G, Crovato F, Marcuccio C, Fumarola D, Scarpa C. Lyme disease in Italy. Zbl Bakt Hyg 1986;A263 459-63.

39 Dournon E, Assous M. Lyme disease in France. Z $\mathrm{bl} \mathrm{Bakt}$ Hyg 1986;A263:464-5.

40 Bózsik BP, Lakos A, Budai J, Telegdy L, Ambrózy G. Occurrence of Lyme Borreliosis in Hungary. Zblt Bakt Hyg 1986;A263:466-7.

41 Kmety E, Rehácek J, Vyrosteková V. Investigations of ticks for the presence of Borrelia in Czechoslovakia. Z $\mathrm{bl} \mathrm{Bakt}$ Hyg 1986;A263:468-70.

42 Korenberg EI, Krychechnikov VN, Ananyina YuV, Chernukha YuG. Prerequisites of the existence of Lyme disease in the USSR. Zbl Bakt Hyg 1986;A263:471-2.

43 Shamroth L. The disorders of cardiac rhythm. Oxford: Blackwell Scientific Publications, 1980:191-2.

44 Cornuau C, Bernard M, Daumas PL, Oblet B, Poirot G Cornuau C, Bernard M, Daumas PL, Oblet B, Poirot G,
Valois M. Les manifestations cardiaques de la maladie de Lyme. A propos de deux observations. (Cardiac manifestations of Lyme disease. Apropos of 2 cases). Ann Cardio Angeiol (Paris) 1984;33:395-9.

45 Allal J, Coisne D, Thomas P, et al. Manifestations cardiaques de la maladie de Lyme. (Cardiac manifestations of Lyme disease). Ann Med Interne (Paris) 1986;137:372-4.

46 Duray PH, Steere AC. Clinical pathologic correlations of Lyme disease by stage. Ann NY Acad Sci 1988;539:65-79.

47 Marcus LC Steere AC Duray PH, Anderson AE Mahoney EB. Fatal pancarditis in a patient with coexistent disease and myocardium. Ann Intern Med 1985;103:374-6.

48 O'Conell JB, Henkin RE, Robinson JA, et al. Gallium-67 imaging in patients with dilated cardiomyopathy and imaging in patients with dilated cardiomyopathy and
biopsy-proven myocarditis. Circulation 1984;70: $58-62$. 